\section{Cell Envelopes of Francisella tularensis: Immunogenic Ac- tivity and Toxicity}

\author{
Balakhonov SV*, Dubrovina VI, Voitkova VV, Korytov KM, \\ Starovoitova TP, Ivanova TA, Korneva AV, Nikolaev VB and \\ Shkaruba TT
}

Department of Medical Sciences, Irkutsk Antiplague Research Institute of Siberia and Far East, Irkutsk, Russia

\begin{abstract}
At present, development of effective vaccines of new generation is an actual problem, in particular concerning the tularemia causative agent. It determines the need to search antigen determinants with high immunogenic activity. Some authors demonstrate that outer membrane proteins of Francisella tularensis possess immunological activity. This fact gave occasion to isolation and comprehensive study of Francisella tularensis cellular envelopes as a perspective component in vaccine engineering.

Toxicity and immunogenic activity of Cell Envelopes (CE) of Francisella tularensis different subspecies is complex studied. It is shown that these preparations in doses $6.3 ; 19.0 ; 57.0$ and $100 \mu \mathrm{g}$ fail to possess toxicity. The immunizing dose $(95 \mu \mathrm{g})$ of CE Francisella tularensis subsp. holarctica 306, Francisella tularensis subsp. mediasiatica A-61 and Francisella tularensis subsp. tularensis B-399 A-Cole protecting white mice against experimental tularemia infection was determined.

It is experimentally demonstrated that $83 \%$ animals survive only after using CE Francisella tularensis subsp. mediasiatica A-61. It is shown that $F$. tularensis $C E$ preparations influence on activation of $T$ and $B$ lympho-cytes of white mice blood cells.

New data concerning the possibility of $F$. tularensis antigen preparation application for increase of experimental animal resistance to $F$. tularensis are obtained. On the basis of the findings there is need for the further detailed investigation of immunogenic properties of CE $F$. tularensis subsp. holarctica 306, F. tularensis subsp. mediasiatica A-61 and F. tularensis subsp. tularensis B-399 A-Cole as perspective components in development of tularemia vaccines.
\end{abstract}

Keywords: Cell envelope; Flow cytometry; Francisella tularensis; Immunity

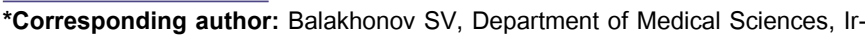
kutsk Antiplague Research Institute of Siberia and Far East, Irkutsk, Russia, Tel: +8 3952220135; E-mail: balakhonov.irk@mail.ru

Citation: Balakhonov SV, Dubrovina VI, Voitkova VV, Korytov KM, Starovoitova TP, et al. (2017) Cell Envelopes of Francisella tularensis: Immunogenic Activity and Toxicity. J Cell Biol Cell Metab 4: 014.

Received: April 03, 2017; Accepted: April 22, 2017; Published: May 05, 2017

\section{Introduction}

At present vaccinal prevention as a priority system of measures aimed at the warning, restriction of distribution and elimination of especially dangerous infectious diseases is of special importance. Live attenuated vaccines developed and introduced in practice still in the $\mathrm{XX}$ century including tularemia vaccine are used as vaccinal preparations for specific prophylaxis of these illnesses. In this connection development of new generation vaccines possessing high immunological and epidemiological efficiency is an actual direction of researches.

The basic antigen determinants are located on surface of Francisella tularensis bacterial cells. So, one of $F$. tularensis immunodominant antigens is Lipopolysaccharide (LPS). However, there are contradicting data in the literature concerning properties of $F$. tularensis external membrane components that can be explained by various methods of its isolation and investigation conditions. There are data that $F$. tularensis LPS does not stimulate immunocompetent cells [1]. Nevertheless, other researchers established activation of mice immunocompetent cells by F. tularensis LPS in case of its dose increase in comparison with standard preparations [2,3]. A number of authors demonstrate that $F$. tularensis outer membrane proteins possess immunological activity [4,5], more than 30 immunoreactive tularemia agent antigens are included into its composition. It is known that $F$. tularensis outer membrane proteins influence on specificity of macroorganism immune response, possess unique polyepitope antigenic structure and are considered as perspective components in engineering of subunit chemical vaccines.

The aforesaid has formed the basis for isolation and comprehensive studying of $F$. tularensis cell envelopes as a perspective component in vaccine developments [6,7].

The aim of this investigation included the detection of toxicity of the resulted CE F. tularensis different subspecies and its immunizing dose with subsequent estimation of the functional activity of experimental animal blood cells under the influence of these preparations in vivo and in vitro.

\section{Materials and Methods}

Cell envelopes of $\boldsymbol{F}$. tularensis: Cell Envelopes (CE) prepared by lysis of live cells from $6 F$. tularensis strains: F. tularensis subsp. novicida Utah 112 [6], F. tularensis subsp. mediasiatica A-61, F. tularensis subsp. tularensis B-399 A-Cole, F. tularensis subsp. holarctica 21/400, F. tularensis subsp. holarctica 306, F. tularensis subsp. holarctica 15 NIIEG from the collection of Irkutsk Antiplague Research Institute were used in this work.

Experimental animals: The tests were performed using adult certificated outbred white mice (from Scientific Production Association "Vektor", Novosibirsk city) both sexes, weighing 22-24 g. Manipulations with experimental animals carried out in concordance with the international principles of the Helsinki declaration concerning to the humane relation to animals.

Immunizing Dose (ID) and protective activity: Immunizing Dose (ID) и protective activity of CE was detected using 114 white mice. 
Animals were divided into six experimental groups in 18 white mice in each group and one control in 6 mice. F. tularensis CE preparations were injected subcutaneously into the right leg in volume $0.5 \mathrm{ml}$ in three doses: 3.8; 19 and $95 \mu \mathrm{g}$ (at recalculation to protein). Control animals were injected the same volume of $\mathrm{NaCl}$ isotonic solution, $\mathrm{pH}$ 7.2. At 28 days after immunization white mice were injected subcutaneously a bacterial suspension of high virulent $F$. tularensis subsp. holarctica 306 (Dcl 1) strain in dose of $100 \mathrm{CFU}$ per an animal.

Toxicity of CE F. tularensis: Toxicity of CE F. tularensis different subspecies was determined in 125 white mice as experimental models. Animals were divided into 24 experimental and one control groups (5 mice in each group). White mice were immunized once subcutaneously with CE preparations of $F$. tularensis different subspecies in the right leg in volume of $0.5 \mathrm{ml}$ in a dose $6.3 ; 19.0 ; 57.0$ and $100 \mu \mathrm{g}$ (at recalculation to protein). Control animals were injected the same volume of $\mathrm{NaCl}$ isotonic solution, $\mathrm{pH}$ 7.2.

Flow cytometry: Functional activity of blood cells was examined by a flow cytometry method in vivo and in vitro. Total 120 white mice were used in vitro experiments. Leukocytes isolated from heparinized blood using $3 \%$ gelatin were tested. Cells in concentration of $10^{6}(50$ $\mu \mathrm{l})$ were incubated during $60 \mathrm{~min}$ with CE $F$. tularensis preparations in two doses (19 and $95 \mu \mathrm{g}$ to protein). Immunogenic activity of CE F. tularensis was examined in 60 white mice in vivo. In this case the animals were immunized with CE $F$. tularensis preparations in dose $95 \mu \mathrm{g} / 0.2 \mathrm{ml}$ of buffered physiological solution per an animal. Blood sampling was performed in 3 days after injection of the experimental preparations. The phenotype of white mice blood cells was defined using monoclonal antibodies by Becton Dickinson Company (USA) in the following panel: CD45-APC/CD3-FITC/CD4-Alexa-700/ CD8-APC-Cy7/CD25-PE-Cy7/Annexin-PE/7-AAD. Stained samples were analyzed on flow cytofluorometer BD FACSCanto ${ }^{\mathrm{TM}}$ II. Total activated T-lymphocytes $\left(\mathrm{CD}^{+}{ }^{+} \mathrm{CD} 25^{+}\right)$, activated T-helpers $\left(\mathrm{CD}^{+} \mathrm{C}^{-}\right.$ $\left.\mathrm{D} 4^{+} \mathrm{CD} 25^{+}\right)$and activated B-lymphocytes $\left(\mathrm{CD} 3 \mathrm{CD}^{-} 9^{+} \mathrm{CD} 25^{+}\right)$were detected. Also viability of the cell populations by percentage of live cells $\left(\mathrm{AnV}-7-\mathrm{AAD}^{-}\right)$, necrotic cells $\left(\mathrm{AnV}^{-7}-\mathrm{AAD}^{+}\right)$, cells at the stage of early $\left(\mathrm{AnV}^{+} 7-\mathrm{AAD}^{-}\right)$and late $\left(\mathrm{AnV}^{+} 7-\mathrm{AAD}^{+}\right)$apoptosis was estimated in vitro.

Statistical analysis: Statistical data were processed using parametrical $\mathrm{t}$-criterion with the Bonferroni adjustment. $\mathrm{P}<0.05$ was considered significant.

\section{Results}

It was shown that cell envelope preparations of $F$. tularensis different subspecies in doses $6.3 ; 19.0 ; 57.0$ and $100 \mu \mathrm{g}$ were non-toxic for experimental animals $\left(\mathrm{LD}_{50}\right.$ is not determined). Dissection at the place of the preparation injections revealed no alterations in kidneys, adrenal glands, lungs, heart and other organs. At the same time, alterations in spleen and lymph nodes were observed in case of $F$. tularensis subsp. holarctica 15 NIIEG, CE F. tularensis subsp. novicida Utah 112, F. tularensis subsp. tularensis B-399 A-Cole and F. tularensis subsp. mediasiatica A-61 injections indicating immune reorganization of organism.

Experiments for ID (Table 1) detection of the tested preparations showed that CE F. tularensis subsp. holarctica 306, F. tularensis subsp. mediasiatica A-61 and F. tularensis subsp. tularensis B-399 A-Cole in dose of $95 \mu \mathrm{g}$ protected experimental animals in the infectious process caused by high virulent $F$. tularensis subsp. holarctica 306 strain. Thus only in case of CE F. tularensis subsp. mediasiatica A-61 application the survival rate of the animals was $83 \%$, CE F. tularensis subsp. holarctica $306-33 \%$, CE F. tularensis subsp. tularensis B-399 A-Cole - 17 $\%$.

\begin{tabular}{|c|c|c|c|c|c|}
\hline \multirow{2}{*}{ CE F. tularensis } & \multirow{2}{*}{ ID, mkg } & \multicolumn{3}{|c|}{ Number of animals } & \multirow{2}{*}{$\mathrm{ID}_{50}(\mathrm{mkg})$} \\
\hline & & Tested & Died & Survived & \\
\hline \multirow{3}{*}{$\begin{array}{c}\text { F. tularensis } \\
\text { subsp. holarctica }\end{array}$} & 95 & 6 & 6 & 0 & \multirow{3}{*}{$95<$} \\
\hline & 19 & 6 & 6 & 0 & \\
\hline & 3.8 & 6 & 6 & 0 & \\
\hline \multirow{3}{*}{$\begin{array}{c}\text { F. tularensis } \\
\text { subsp. holarctica }\end{array}$} & 95 & 6 & 6 & 0 & \multirow{3}{*}{$95<$} \\
\hline & 19 & 6 & 6 & 0 & \\
\hline & 3.8 & 6 & 6 & 0 & \\
\hline \multirow{3}{*}{$\begin{array}{c}\text { F. tularensis } \\
\text { subsp. holarctica }\end{array}$} & 95 & 6 & 4 & 2 & \multirow{3}{*}{124.94} \\
\hline & 19 & 6 & 6 & 0 & \\
\hline & 3.8 & 6 & 6 & 0 & \\
\hline \multirow{3}{*}{$\begin{array}{c}\text { F. tularensis } \\
\text { subsp. Novicida }\end{array}$} & 95 & 6 & 6 & 0 & \multirow{3}{*}{164.18} \\
\hline & 19 & 6 & 6 & 0 & \\
\hline & 3.8 & 6 & 5 & 1 & \\
\hline \multirow{2}{*}{$\begin{array}{c}\text { F. tularensis } \\
\text { subsp. Mediaasiatica }\end{array}$} & 95 & 6 & 1 & 5 & \multirow{3}{*}{43.17} \\
\hline & 19 & 6 & 5 & 1 & \\
\hline A-61 & 3.8 & 6 & 6 & 0 & \\
\hline \multirow{3}{*}{$\begin{array}{c}\text { F. tularensis } \\
\text { subsp. Tularensis }\end{array}$} & 95 & 6 & 5 & 1 & \multirow{3}{*}{164.18} \\
\hline & 19 & 6 & 6 & 0 & \\
\hline & 3.8 & 6 & 6 & 0 & \\
\hline контроль & & 6 & 5 & 0 & \\
\hline
\end{tabular}

Table 1: Immunizing dose and protective activity of cell envelopes after $F$. tularensis subsp. holarctica 306 subcutaneous injection to experimental animals.

The results demonstrated that the experimental F. tularensis preparations in doses of 19 and $95 \mu \mathrm{g} / 10^{6}$ leukocytes in vitro failed to affect statistically on the expression level of early activation marker (CD25) of T- and B-lymphocytes. Preparations of CE F. tularensis different subspecies in these doses did not influence on necrosis and apoptosis processes in experimental animal blood cells.

Experiments in vivo showed that statistically significant $(\mathrm{P}<0.05)$ increase of activated B-lymphocytes in comparison with the controls $(2.6 \pm 0.4 \%)$ was registered in 3 days after white mice immunization with CE F. tularensis subsp. mediasiatica A-61 (4.1 $\pm 0.6 \%)$ and F. tularensis subsp. tularensis B-399 A-Cole (3.4 $\pm 0.8 \%)$. At the same time CE F. tularensis subsp. holarctica 15 NIIEG and F. tularensis subsp. holarctica 306 promoted the percentage increase of T- lymphocytes in 1.2 times (Table 2).

\section{Discussion}

It is known that macrophages are important in development of the infectious process caused by $F$. tularensis being both a primary target and also a site of bacteria localization and reproduction. Activation of intracellular signal pathways of immunocompetent cells causing the secretion of cytokines and chemokines is mediated by interaction of microbic components with pattern-discriminating macrophage receptors. So, Bacterial Lipopeptide (BLP), lipoproteins, Lipopolysaccharide (LPS) and also many other proteins (FopA, FopC, TUL4, FslE, FmvB and others) are located on surface of bacterial cells, in particular 


\begin{tabular}{|c|c|c|c|}
\hline \multirow{2}{*}{ CE F.tularensis } & \multicolumn{3}{|c|}{ Index, \% } \\
\hline & $\mathrm{CD}^{+}{ }^{+} \mathrm{CD} 25^{+}$ & $\mathrm{CD}^{+}{ }^{+} \mathrm{CD} 4^{+} \mathrm{CD}^{25^{+}}$ & $\mathrm{CD}^{-\mathrm{CD} 19^{+} \mathrm{CD} 25^{+}}$ \\
\hline $\begin{array}{c}\text { F. tularensis } \\
\text { subsp. holarctica } \\
15 \text { NIIEG }\end{array}$ & $11.1 \pm 0.9^{*}$ & $9.7 \pm 0.6$ & $2.9 \pm 0.3$ \\
\hline $\begin{array}{c}\text { F. tularensis } \\
\text { subsp. holarctica } \\
306\end{array}$ & $12.0 \pm 0.8^{*}$ & $9.9 \pm 0.5$ & $2.4 \pm 0.3$ \\
\hline $\begin{array}{l}\text { F. tularensis } \\
\text { subsp. novicida } \\
\text { Utah } 112\end{array}$ & $10.1 \pm 0.8$ & $7.0 \pm 0.6$ & $2.6 \pm 0.4$ \\
\hline $\begin{array}{c}\text { F. tularensis } \\
\text { subsp. mediaasiatica } \\
\text { A-61 }\end{array}$ & $8.3 \pm 1.0$ & $7.1 \pm 0.7$ & $4.1 \pm 0.6^{*}$ \\
\hline $\begin{array}{l}\text { F. tularensis } \\
\text { subsp. tularensis } \\
\text { B-399 A-Cole }\end{array}$ & $8.0 \pm 0.9$ & $7.4 \pm 0.7$ & $3.4 \pm 0.8^{*}$ \\
\hline Conrtol & $9.8 \pm 0.7$ & $8.2 \pm 0.8$ & $2.6 \pm 0.4$ \\
\hline
\end{tabular}

Table 2: Functional activity of blood lymphocytes of white mice immunized by CE F. tularensis.

Note: * $-\mathrm{P}<0.05$

F. tularensis. Due to outer membrane proteins possess higher immunogenic activity in comparison with LPS [4], studying of CE F. tularensis is a fundamental basis for interpretation of intracellular survival mechanisms, interaction of bacteria with macroorganism cells and a perspective direction in search of components for development of tularemia vaccine.

The conducted examinations demonstrated that CE from F. tularensis subsp. novicida Utah 112, F. tularensis subsp. mediasiatica A-61, F. tularensis subsp. tularensis B-399 A-Cole, F. tularensis subsp. holarctica 21/400, F. tularensis subsp. holarctica 306, F. tularensis subsp. holarctica 15 NIIEG strains in doses 6.3; 19.0; 57.0 and $100 \mu \mathrm{g}$ were non-toxic for experimental animals. This fact was confirmed by the results of pathomorphological analysis of white mice organs immunized with these preparations and also by the indicators of blood cell viability at interaction with $\mathrm{CE} F$. tularensis in vitro.

The immunizing dose (95 $\mu \mathrm{g})$ of F. tularensis subsp. holarctica 306, F. tularensis subsp. mediasiatica A-61 and F. tularensis subsp. tularensis B-399 A-Cole protecting white mice from experimental tularemia infection was established.

There are literature data that the preparations containing F. tularensis external membrane proteins possess immunological activity in $19 \mu \mathrm{g}$ dose [4,5]. In this connection CE F. tularensis in two doses: 19 and $95 \mu \mathrm{g}$ was used in our experiments to estimate functional activity of blood cells of the laboratory animals by flow cytometry method. It was experimentally demonstrated that CE F. tularensis preparations rendered multidirectional influence on activation of T- and B-lymphocytes of white mice blood cells. So, CE F. tularensis subsp. mediasiatica A-61 and F. tularensis subsp. tularensis B-399 A-Cole preparations possessing immunogenic activity (the survival rate was $83 \%$ and $17 \%$ of animals, respectively) resulted in increase of $\mathrm{CD} 3 \mathrm{CD}^{-} 9^{+} \mathrm{C}-$ $\mathrm{D} 25^{+}$-lymphocyte percentage, and F. tularensis subsp. holarctica 306 $\mathrm{CE}(33 \%)$ - $\mathrm{CD}^{+} \mathrm{CD} 25^{+}$- lymphocyte.
The distinctions in protective activity of the preparations and their ability to increase functional activity of white mice lymphocytes determined during the examination can be possibly caused by nucleotide polymorphism of the genes coding outer membrane proteins [8], and variability of LPS structure $[9,10]$ in F. tularensis subspecies that undoubtedly affects on the bacteria virulence.

Formerly we determined that CE $F$. tularensis stimulated IL- $1 \beta$, TNF- $\alpha$, IL-2, GM-CSF and G-CSF production by immunocompetent cells of the experimental animals in vivo [6,7].

On the basis of the conducted investigations it is possible to conclude that CE preparations of $F$. tularensis subsp. holarctica 306, F. tularensis subsp. mediasiatica A-61 and F. tularensis subsp. tularensis B-399 A-Cole possess protective activity, ability to increase functional activity of blood lymphocytes and stimulate production of proinflammatory cytokines by white mice immunocompetent cells. At the same time the further complex research of immunogenic properties of these preparations as perspective components in development of tularemia vaccines is required.

\section{References}

1. Dreisbach VC, Cowley S, Elkins KL (2000) Purified lipopolysaccharide from Francisella tularensis live vaccine strain (LVS) induces protective immunity against LVS infection that requires B cells and gamma interferon. Infect Immun 68: 1988-1996.

2. Ancuta P, Pedron T, Girard R, Sandström G, Chaby R (1996) Inability of the Francisella tularensis lipopolysaccharide to mimic or to antagonize the induction of cell activation by endotoxins. Infect Immun 64: 2041-2046.

3. Rahhal RM, Vanden Bush TJ, McLendon MK, Apicella MA, Bishop GA (2007) Differential effects of Francisella tularensis lipopolysaccharide on B lymphocytes. Journal of Leukocyte Biology 82: 813-820.

4. Huntley JF, Conley PG, Rasko DA, Hagman KE, Apicella MA, et al. (2008) Native outer membrane proteins protect mice against pulmonary challenge with virulent type A Francisella tularensis. Infect Immun 76: 3664-3671.

5. Hickey AJ, Hazlett KR, Kirimanjeswara GS, Metzger DW (2011) Identification of Francisella tularensis outer membrane protein A (FopA) as a protective antigen for tularemia. Vaccine 29: 6941-6947.

6. Korneva AV, Nikolaev VB, Yastremskaya KYu, Markov EYu, Voytkova VV, et al. (2014) Results of the study of the immunogenic activity of cellular membranes Francisella tularensis different subspecies (report 1). Epidemiology and Vaccine Prevention 4: 73-77.

7. Korneva AV, Nikolaev VB, Yastremskaya KYu, Markov EYu, Voytkova VV, et al. (2015) Results of the study of the immunogenic activity of cell envelopes of Francisella tularensis different subspecies (report 2). Bulletin of the East Siberian Scientific Center SBRAMS 1: 63-66

8. Nübel $U$, Reissbrodt $R$, Weller $A$, Grunow R, Porsch-Ozcürümez $M$, et al. (2006) Population structure of Francisella tularensis. J Bacteriol 188: 53195324.

9. Gunn JS, Ernst RK (2007) The Structure and Function of Francisella Lipopolysaccharide. Ann N Y Acad Sci 1105: 202-218.

10. Mokrievich AN, Kondakova AN, Valade E, Platonov ME, Vakhrameeva GM et al. (2010) Biological properties and structure of the lipopolysaccharide of a vaccine strain of Francisella tularensis generated by inactivation of a quorum sensing system gene qseC. Biochemistry (Mosc) 75: 443-451. 